\title{
A peridynamic damage-cumulative hybrid model for fatigue cracking
}

\author{
Lanwen WANG ${ }^{1}$, Xuanyu Sheng ${ }^{1}$, and Jianbin Luo ${ }^{1}$ \\ ${ }^{1}$ Tsinghua University Department of Mechanical Engineering
}

October 18, 2021

\begin{abstract}
A new peridynamic fatigue damage-cumulative hybrid model is developed in this study, which is modeled by Kinetic Theory of Fracture(KTF) and Paris formula. The compact tension specimen and modified compact tension specimen are used to study the convergence of the fatigue crack growth path and fatigue life. Then constant amplitude cyclic loading and variable amplitude cyclic loading of the specimens are simulated. By comparing with the experimental results, the accuracy of the model is verified. Compared with the fatigue model that only uses KTF, the hybrid model predicts the fatigue crack growth rate more accurately. The model is based on the stress damage criterion in the fatigue crack initiation stage, which can be a basis for fatigue prediction and safety design of components in complex stress state in actual engineering.
\end{abstract}

\section{Hosted file}

manuscript. docx available at https://authorea.com/users/441675/articles/542132-a-peridynamicdamage-cumulative-hybrid-model-for-fatigue-cracking 